\title{
Update from the European Association of Urology (EAU) Annual Meeting 2016
}

\section{Anil Kapoor, MD, FRCSC}

Professor of Surgery (Urology), McMaster University, Associate Editor (Oncology), Canadian Urological Association Journal (CUA), Hamilton, ON, Canada

Cite as: Can Urol Assoc J 2016;10(5-6Supp|2):S123. http://dx.doi.org/10.5489/cuai.3912

$\mathrm{T}$

he European Association of Urology (EAU) Annual Meeting provides high-caliber, cutting-edge research in all facets of the urology spectrum. The 2016 EAU Annual Meeting in Munich was no exception, with groundbreaking research in urologic oncology, functional urology, and testosterone deficiency.

In this supplement, we summarize for you some of the wide variety of research presented this year. Dr. Sender Herschorn describes new research in the treatment of overactive bladder $(\mathrm{OAB})$ and lower urinary tract symptoms
(LUTS). Dr. Alexandre Zlotta and I have summarized some key research in prostate cancer, kidney cancer, and bladder cancer. We finish with some new data on testosterone replacement benefits and cardiovascular considerations. We hope you benefit from this EAU 2016 report for your Spring reading!

Competing interests: None of the authors have received any honoraria for preparation of this EAU 2016 report.

Correspondence: Dr. Anil Kapoor, McMaster University, Hamilton, ON, Canada; akapoor@mcmaster.ca 